\title{
LA EVALUACIÓN DEL ABUSO SEXUAL EN PERSONAS CON DISCAPACIDAD INTELECTUAL: PROCESO DE CONSTRUCCIÓN Y VALIDACIÓN DE UN INSTRUMENTO DE AUTOINFORME
}

\author{
Gil-Llario, M.D. \\ Dpto de Psicología Evolutiva y de la Educación, \\ Universitat de València, Valencia, España \\ Dolores.Gil@uv.es \\ Ballester-Arnal, R. \\ Departamento de Psicología Básica, Clínica y Psicobiología, \\ Universidad Jaume I de Castellón, España \\ Fernández-García, 0. \\ Dpto de Psicología Evolutiva y de la Educación, \\ Universitat de València, Valencia, España \\ Caballero-Gascón, L. \\ Dpto de Psicología Evolutiva y de la Educación, \\ Universitat de València, Valencia, España \\ Morell-Mengual, v. \\ Dpto de Psicología Evolutiva y de la Educación, \\ Universitat de València, Valencia, España
}

Fecha de Recepción: 15 Mayo 2018

Fecha de Admisión: 1 Octubre 2018

\begin{abstract}
RESUMEN
Las personas con diversidad funcional presentan ciertas limitaciones en el funcionamiento de su día a día, lo que les convierten en dependientes de sus cuidadores principales, quedando su cuerpo expuesto a ellos. Además, presentan menos recursos para detectar y defenderse ante situaciones de abuso. Estos factores, entre otros, hacen que se conviertan en un colectivo vulnerable al abuso sexual. Pero en la detección de las víctimas potenciales, nos encontramos con limitaciones en comprensión y lectoescritura, lo que hace cuestionar la fiabilidad de la información obtenida. El objetivo de este estudio, es la elaboración de un instrumento fiable y válido que se adapte a las características de las personas con diversidad funcional, y posibilite la detección de casos de abuso sexual. Para ello, el proceso de construcción-validación de la escala se ha realizado en dos fases generándose, en cada una de ellas, diferentes versiones que se han aplicado a dos grupos de participantes. Se detalla el análisis que el grupo de expertos ha realizado a partir de las dos aplicaciones piloto y las consecuentes modificaciones derivadas de dichos análisis. En la primera fase la versión se aplica a 20 participantes y en la segunda a 150. La versión final cuenta con una fiabilidad de .91. El estudio ha mostrado la complejidad que supone elaborar un instrumento de evaluación del abuso sexual para personas con discapacidad intelectual por las limitaciones de comprensión inherentes
\end{abstract}




\section{LA EVALUACIÓN DEL ABUSO SEXUAL EN PERSONAS CON DISCAPACIDAD INTELECTUAL: PROCESO DE CONSTRUCCIÓN Y VALIDACIÓN DE UN INSTRUMENTO DE AUTOINFORME}

al colectivo, remarcando la importancia de contar con las aportaciones de profesionales que trabajan diariamente con ellos.

Palabras clave: abuso sexual; instrumento; diversidad funcional; construcción; validación

\section{ABSTRACT \\ THE EVALUATION OF SEXUAL ABUSE IN PERSONS WITH INTELLECTUAL DISABILITIES: CONSTRUCTION AND VALIDATION PROCESS OF A SELF-REPORTING INSTRUMENT.}

People with functional diversity have certain limitations in the functioning of their daily life, which makes them dependent on their primary caregivers, leaving their bodies exposed to them. In addition, they have fewer resources to detect and defend themselves against abuse. These factors, among others, make them a group vulnerable to sexual abuse. But in the detection of potential victims, we find limitations in comprehension and literacy, which makes questioning the reliability of the information obtained. The objective of this study is the development of a reliable and valid instrument adapted to the characteristics of people with functional diversity and allows the detection of cases of sexual abuse. In order to do so, the construction-validation process of the scale has been carried out in two phases, generating, in each of them, different versions that have been applied to two groups of participants. It details the analysis that the group of experts has made from the two pilot applications and the consequent modifications derived from these analyzes. In the first phase the version applies to 20 participants and in the second to 150 . The final version has a reliability of .91. The study has shown the complexity of developing an instrument for assessing sexual abuse for people with intellectual disabilities because of the limitations of understanding inherent in the collective, stressing the importance of having the contributions of professionals who work daily with them.

Keywords: sexual abuse; instrument; functional diversity; construction; validation

\section{INTRODUCCIÓN}

La diversidad funcional, entendiéndola como "la diferencia en el funcionamiento de una persona al realizar tareas habituales de manera distinta a la mayoría de la población" (F.V.I. 2005), conlleva una serie de limitaciones en el aprendizaje de habilidades para el funcionamiento de la vida diaria y en la respuesta a diferentes situaciones. Estas dificultades se dejan entrever principalmente en sus entornos más próximos donde desarrollan relaciones de dependencia y se gestan, en muchos casos, situaciones de abuso.

En general, las personas con diversidad funcional disponen de menos recursos personales y sociales para defenderse de agresiones, experimentando mayores dificultades para identificar, expresar y/o denunciar circunstancias de abuso (Consejería para la Igualdad y Bienestar Social de la Junta de Andalucía, 2008). Esto les deja más expuestos y les hace más vulnerables a ser víctimas, ante la creencia popular de que son "insensibles al dolor", y que no captan ni entienden el abuso del que pueden ser objeto.

En este sentido, la falta de autonomía en las tareas de cuidado personal, que en muchos casos se hace patente, provoca que su cuerpo se interprete como un elemento de total accesibilidad para aquellos que se encargan de ofrecer ese apoyo, pudiendo usarlo para satisfacer sus necesidades sexuales. Todo esto supone que, en muchos casos, quienes sufren la discapacidad puedan llegar a interiorizar la falsa creencia de que su cuerpo es, realmente, "de libre acceso" para sus cuidadores y familiares 0 allegados. Así, la dependencia de otros acaba favoreciendo los comportamientos de sumisión y obediencia puesto que temen que la negación ante el abuso pueda implicar la retirada del apoyo que requieren; y es precisamente esa necesidad de apoyo lo que puede llevarles a querer contentar a aquellos que están a su alrededor (Verdugo, Alcedo, Bermejo y Aguado, 2002). 
Estaríamos, entonces, ante casos en los que las víctimas se ven sometidas a una supuesta gratificación personal hacia el agresor por sus cuidados y atenciones, haciendo que éste se tome la libertad de 'utilizarles' sexualmente (González y Ramos, 2016). A esto se sumarían las creencias en cuanto a que las personas con diversidad funcional no tienen necesidades sexuales y el miedo a que hablar de ello pueda animarles a tener un comportamiento sexual incontrolado. Esto bloquea su acceso a una educación afectivo-sexual impidiéndoles, al mismo tiempo, aprender a discriminar cuáles son los comportamientos sexuales adecuados y a detectar cuándo están siendo víctimas de abuso (Verdugo, Alcedo, Bermejo y Aguado, 2002).

Aunque queda probado que las personas con diversidad funcional, y en concreto con discapacidad intelectual, son un colectivo de riesgo siendo víctimas de abuso sexual en mayor proporción que la población general; carecemos de cifras válidas acerca de la prevalencia real del abuso sexual en este colectivo.

A la hora de extraer información a este colectivo nos enfrentamos a sus limitaciones intelectuales, así como en habilidades comunicativas y sociales, lo cual dificulta mucho el proceso de evaluación. Por ello, en muchos casos se recurre a los familiares como informadores directos si bien éstos frecuentemente desatienden el discurso de la propia víctima ignorando posibles casos de abuso (González y Ramos, 2016).

Además, en los pocos estudios que informan de ello, los datos vienen presentados conjuntamente con otros tipos de abuso (físico, verbal, psicológico, etc.), y se centran sobre todo en casos de abuso sexual informado por adultos (Couwenhoven, 2013). Las cifras así obtenidas indican que entre los adultos con discapacidad intelectual y/o física, un $83 \%$ de mujeres y un $32 \%$ de hombres son víctimas reales de abuso sexual presentando una mayor probabilidad de ser agredidas repetidas veces, quedando reflejado que tan sólo se informa de un escaso $3 \%$ de todos los casos de agresión (Couwenhoven, 2013). Estas cifras no permiten justificar la necesidad de intervención para prevenir el abuso sexual ya que de forma falaz la prevalencia es baja. Por estos motivos, el objetivo de este estudio es elaborar una escala fiable y válida, adaptada a las características de la población con discapacidad intelectual, que permita detectar casos de abuso sexual.

El proceso de construcción-validación del instrumento se ha realizado en dos fases que se describen a continuación. En cada una de ellas se han generado diferentes versiones que se han aplicado a dos grupos diferentes de participantes.

\section{MÉTODO}

\section{FASE 1.}

\section{a) Procedimiento}

En primer lugar se partió de la "Illustrated Scale Measuring the Sexual-Abuse Prevention Knowledge" elaborada por Wen-Ying Liou en 2013 y validada en alumnas con discapacidad intelectual que estudiaban en escuelas de educación especial de Taiwán. Esta escala apoyada por ilustraciones consta de 20 ítems dicotómicos (verdadero/falso) y 10 ítems de respuesta múltiple que evalúan: la fisiología en la pubertad (ítems 1, 2, 3, 4, 21, 22), los límites físicos (ítems 5, 6, 7, 8, 23, 24), la identificación de relaciones sexuales inapropiadas (ítems $9,10,11,12,25,26$ ), la identificación de situaciones abusivas (ítems $13,14,15,16,27,28$ ) y los mecanismos de afrontamiento ante situaciones de abuso sexual (ítems 17, 18, 19, 20, 29, 30). El análisis de fiabilidad de la escala mostró un valor de .81 para los ítems dicotómicos, .74 para los ítems de opción múltiple, y .84 para la escala entera. Dicha escala fue traducida de forma literal con las adaptaciones culturales pertinentes manteniendo el mismo número de ítems y ambos formatos de respuesta (dicotómico y respuesta múltiple). 
b) Participantes y resultados

Esta versión del instrumento fue aplicada a 20 adultos con diversidad funcional con edades comprendidas entre los 27 y los 55 años que eran usuarios de diversos centros ocupacionales de Andalucía. El proceso de evaluación lo llevaron a cabo dos profesionales del equipo de investigación que conocían el instrumento y tenían contacto directo y continuado con los usuarios. Ambos fueron los encargados de, tras el pase del instrumento, analizar por separado su experiencia respecto a: el grado de facilidad para comprender los ítems, la correspondencia con el objetivo de evaluación y la adecuación a las características de los usuarios (edad, características del trastorno, etc.). Seguidamente se analizó el grado de acuerdo entre los evaluadores en cuanto a la pertinencia de mantener cada ítem, estableciéndose que se aceptarían solo cuando hubiera máximo acuerdo entre ambos (100\%).

Tabla 1. Acuerdo entre evaluadores en la fase 1 del estudio piloto.

\begin{tabular}{ccccc}
\hline Ítem & Profesional 1 & Profesional 2 & Grado de acuerdo & Decisión \\
\hline $\mathbf{1}$ & 0 & 0 & $100 \%$ & Eliminar \\
$\mathbf{2}$ & 0 & 0 & $100 \%$ & Eliminar \\
$\mathbf{3}$ & 0 & 0 & $100 \%$ & Eliminar \\
$\mathbf{4}$ & 0 & 0 & $100 \%$ & Eliminar \\
$\mathbf{5}$ & 1 & 1 & $100 \%$ & Mantener \\
$\mathbf{6}$ & 1 & 0 & $0 \%$ & Valorar por expertos \\
$\mathbf{7}$ & 1 & 1 & $100 \%$ & Mantener \\
$\mathbf{8}$ & 1 & 0 & $0 \%$ & Valorar por expertos \\
$\mathbf{9}$ & 0 & 1 & $0 \%$ & Valorar por expertos \\
$\mathbf{1 0}$ & 0 & 1 & $0 \%$ & Valorar por expertos \\
$\mathbf{1 1}$ & 0 & 1 & $0 \%$ & Valorar por expertos \\
$\mathbf{1 2}$ & 0 & 1 & $0 \%$ & Valorar por expertos \\
$\mathbf{1 3}$ & 0 & 1 & $0 \%$ & Valorar por expertos \\
$\mathbf{1 4}$ & 1 & 0 & $0 \%$ & Valorar por expertos \\
$\mathbf{1 5}$ & 0 & 0 & $100 \%$ & Eliminar \\
$\mathbf{1 6}$ & 1 & 1 & $100 \%$ & Mantener \\
$\mathbf{1 7}$ & 1 & 1 & $100 \%$ & Mantener \\
$\mathbf{1 8}$ & 1 & 0 & $0 \%$ & Valorar por expertos \\
$\mathbf{1 9}$ & 1 & 1 & $100 \%$ & Mantener \\
$\mathbf{2 0}$ & 0 & 1 & $0 \%$ & Valorar por expertos \\
$\mathbf{2 1}$ & 0 & 0 & $100 \%$ & Eliminar \\
$\mathbf{2 2}$ & 0 & 0 & $100 \%$ & Eliminar \\
$\mathbf{2 3}$ & 0 & 0 & $100 \%$ & Eliminar \\
$\mathbf{2 4}$ & 0 & 0 & $100 \%$ & Eliminar \\
$\mathbf{2 5}$ & 0 & 0 & $100 \%$ & Eliminar \\
$\mathbf{2 6}$ & 0 & 0 & $100 \%$ & Eliminar \\
$\mathbf{2 7}$ & 1 & 0 & $0 \%$ & Valorar por expertos \\
$\mathbf{2 8}$ & 1 & 0 & $0 \%$ & Valorar por expertos \\
$\mathbf{2 9}$ & 0 & 1 & $0 \%$ & Valorar por expertos \\
$\mathbf{3 0}$ & 0 & 1 & $0 \%$ & Valorar por expertos \\
\hline & & 1 & & \\
\hline
\end{tabular}

Nota: $1=$ Mantener el ítem; $0=$ Eliminar el ítem

Como podemos ver reflejado de forma resumida en la tabla 1, entre los profesionales hubo un grado de acuerdo del 53,33\% (16 de 30 ítems) en sus decisiones, coincidiendo en que 11 de los ítems debían ser eliminados (36,66\%) y 5 de ellos debían mantenerse sin ningún cambio (16,66\%). En el resto de ítems hubo discrepancias que se tuvieron en cuenta en la revisión por expertos. Los criterios seguidos para eliminar ítems fueron: la no adecuación al objetivo de la evaluación (1, 2, 3, 
$4,21,22)$, la no adecuación a las características de los usuarios (15) y la repetición de contenido $(23,24,25,26)$.

\section{FASE 2.}

\section{a) Procedimiento}

Con los resultados del primer estudio piloto y con la información aportada por los evaluadores, se llevó a cabo una segunda revisión del instrumento donde se valoraron las dificultades que se habían encontrado durante el pase de la escala, con la correspondiente reconstrucción. En la segunda revisión participó un grupo de expertos constituido por investigadores especialistas en educación sexual de dos universidades, la de Valencia y la Jaume I de Castellón, así como por psicólogos en activo considerados especialistas por su larga trayectoria en centros ocupacionales tanto de la Comunidad Valenciana como de Andalucía.

La revisión del instrumento tuvo en cuenta como punto de partida la valoración de los evaluadores siendo el objetivo decidir si los ítems cuestionados debían seguir en la escala con la misma redacción o modificados en algún sentido. La tabla 2 muestra el resultado de dicho análisis.

Tabla 2. Análisis de ítems por el grupo de expertos tras la primera aplicación piloto.

\begin{tabular}{|c|c|c|c|}
\hline Ítem & $\begin{array}{c}\text { Propuesta } \\
\text { evaluadores }\end{array}$ & Decisión expertos & Justificación \\
\hline 1 & 0 & 0 & No se adecúa al objetivo de evaluación \\
\hline 2 & 0 & 0 & No se adecúa al objetivo de evaluación \\
\hline 3 & 0 & 0 & No se adecúa al objetivo de evaluación \\
\hline 4 & 0 & 0 & No se adecúa al objetivo de evaluación \\
\hline 5 & 1 & 1 & Contenido y lenguaje adecuado \\
\hline 6 & ¿? & Reescribir ítem & Adecuar a un lenguaje no sexista \\
\hline 7 & 1 & 1 & Contenido y lenguaje adecuado \\
\hline 8 & ¿? & Reescribir ítem & Adecuar a un lenguaje no sexista \\
\hline 9 & $i ?$ & Reescribir ítem & Adecuar a un lenguaje más sencillo \\
\hline 10 & ¿? & Reescribir ítem & Adecuar a un lenguaje más sencillo \\
\hline 11 & $i ?$ & Reescribir ítem & Adecuar a un lenguaje más sencillo \\
\hline 12 & ¿? & Reescribir ítem & Adecuar a un lenguaje más sencillo \\
\hline 13 & ¿? & Reescribir ítem & Adecuar a un lenguaje más sencillo \\
\hline 14 & ¿? & Reescribir ítem & Adecuar a un lenguaje más sencillo \\
\hline 15 & 0 & 0 & No se adecua al contexto socio-cultural \\
\hline 16 & 1 & 1 & Contenido y lenguaje adecuado \\
\hline 17 & 1 & 1 & Contenido y lenguaje adecuado \\
\hline 18 & ¿? & Reescribir ítem & Adecuar a las características de los evaluados \\
\hline 19 & 1 & 1 & Contenido y lenguaje adecuado \\
\hline 20 & ¿? & Reescribir ítem & Adecuar a un lenguaje asexual y más sencillo \\
\hline 21 & 0 & 0 & No se adecúa al objetivo de la evaluación \\
\hline 22 & 0 & 0 & No se adecúa al objetivo de la evaluación \\
\hline 23 & 0 & 0 & Se superpone con el ítem 7 \\
\hline 24 & 0 & 0 & Se superpone con el ítem 8 \\
\hline 25 & 0 & 0 & No se adecúa al objetivo de la evaluación \\
\hline 26 & 0 & 0 & No se adecúa al objetivo de la evaluación \\
\hline 27 & ¿? & Reescribir ítem & Convertir en dicotómico $(\mathrm{v} / \mathrm{f})$ \\
\hline 28 & ¿? & Reescribir ítem & Convertir en dos ítems dicotómicos (v/f) \\
\hline 29 & ¿? & Reescribir ítem & $\begin{array}{c}\text { Convertir en dos ítems dicotómicos }(\mathrm{v} / \mathrm{f}) \text { y } \\
\text { adecuar lenguaje no sexista }\end{array}$ \\
\hline 30 & ¿? & Reescribir ítem & Convertir en dicotómico $(\mathrm{v} / \mathrm{f})$ \\
\hline
\end{tabular}

Nota: $1=$ Mantener el ítem; $0=$ Eliminar el ítem, $;$ ?=Falta consenso 


\section{LA EVALUACIÓN DEL ABUSO SEXUAL EN PERSONAS CON DISCAPACIDAD INTELECTUAL: PROCESO DE CONSTRUCCIÓN Y VALIDACIÓN DE UN INSTRUMENTO DE AUTOINFORME}

Se llevaron a cabo también varias modificaciones:

Se aprecia que el instrumento está orientado a la evaluación de personas del sexo femenino únicamente, conteniendo ítems que solo pueden contestar mujeres. Esta problemática provoca la obtención de respuestas y resultados sesgados, y limita el acceso a una amplia parte de la población (sexo masculino), que aunque parece enfrentarse a un menor número de situaciones de abuso sigue tratándose de un colectivo de riesgo. Por ello, se decide reescribir muchos de los ítems desde un lenguaje asexual, o teniendo en cuenta la perspectiva masculina también.

Se observa que ambos formatos de preguntas (dicotómicos y de respuesta múltiple) evalúan exactamente los mismos conocimientos superponiéndose y convirtiéndose en redundantes en la mayoría de los casos, sin ser sistemáticos. Se valora que con su eliminación y reescritura se evitará fatigar a los usuarios y se facilitará la comprensión, consiguiendo, por tanto, resultados más fiables.

Se cuestiona la utilidad de los ítems que evalúan los conocimientos sobre cambios fisiológicos y corporales durante la pubertad, ya que se estima que pertenecen a un factor que no contribuye a la detección de un posible abuso sexual. Además, están orientados hacia un colectivo muy concreto (adolescentes), siendo inútiles para población de edades superiores (jóvenes y adultos), ya que preguntan refiriéndose a cambios en ese momento de la pubertad dificultando contestar cuando no se está en esa etapa vital. Esto ocasiona que se lleve a cabo, también, una reestructuración factorial, pasando de 5 a 4 factores teóricos: Ios límites del cuerpo, la identificación de relaciones sexuales inapropiadas, la identificación de situaciones abusivas y los mecanismos de afrontamiento ante situaciones de abuso sexual.

Se insiste en la clarificación de las cuestiones mediante el uso de imágenes sencillas. Se observa que en muchos casos, las carentes habilidades de lectoescritura de los usuarios provocan que no pueda completarse la evaluación. Por ello, se insiste en la importancia de la mejora del apoyo visual para conseguir una mejor comprensión del contenido de los ítems.

También se incorporan 2 ítems de nueva creación que amplían el bagaje alrededor de los conocimientos sobre posibles lugares en los que pueden darse situaciones de abuso. Además, los ítems con anterior formato de alternativas se reescriben en formato dicotómico, debido a que simplifica la respuesta, creando en algunos casos 2 ítems a partir de uno.

Con todo ello, se pasa de 30 ítems (20 en formato dicotómico y 10 en formato alternativas) a 23 ítems (todos en formato dicotómico v/f). De estos, el 21,74\% de los ítems que forman la nueva escala se conservan del primer instrumento, el $69,57 \%$ han sido reescritos a partir de ya existentes y el $8,67 \%$ son ítems de nueva creación.

b) Participantes y resultados de la segunda versión

Una vez realizados todos los cambios expuestos, se llevó a cabo una nueva aplicación de la escala revisada. En ese caso, se aplicó a 150 adultos con discapacidad intelectual y con edades comprendidas entre los 20 y los 67 años, pertenecientes a 15 centros ocupacionales de la Comunidad Valenciana. En el pase del instrumento colaboraron los profesionales de los propios centros ocupacionales, quienes a posteriori también aportaron su valoración ya que conocían a los usuarios por lo que podían corroborar la fiabilidad de los datos recogidos.

Tras la aplicación de la segunda versión del instrumento se extrajeron las características psicométricas. La puntuación media de la escala es de 16,89 (dt=71,56) y los resultados del coeficiente de fiabilidad de la escala completa señalan un alfa de Cronbach de .91, resultado que refleja una excelente consistencia interna entre los ítems. 


\section{CONCLUSIONES}

El objetivo de este estudio ha sido desarrollar un instrumento que garantice la calidad en la detección de casos de abuso sexual en personas con discapacidad intelectual. Los resultados obtenidos tras el análisis y modificación de los ítems de la escala primitiva permite concluir que el instrumento de detección del abuso sexual creado (DAS) no solo puede ser útil para la detección de casos de abuso sexual, sino también para descubrir factores de riesgo que permitan identificar una eventual mayor vulnerabilidad y probabilidad de ser víctima. Se trata de un aspecto de especial relevancia ya que es necesario tener información tanto sobre los factores de vulnerabilidad como sobre los amortiguadores que presenta una persona a la hora de diseñar una intervención efectiva, primaria o secundaria (Recio et. al., 2014).

Cabe resaltar además, los aspectos innovadores del DAS, como la incorporación de imágenes para facilitar la comprensión en aquellos casos en que la persona tenga un nivel en lecto-escritura bajo 0 nulo, en la línea de lo sugerido por Lyden (2007), quien señala que para evaluar el conocimiento sexual de una persona que tiene una comunicación alterada (como las personas con discapacidad intelectual) puede ser útil la utilización de imágenes. Por lo que se refiere al formato, hemos constatado que responden mejor ante ítems dicotómicos v/f que de respuesta múltiple, ya que debido a su falta de flexibilidad mental, baja memoria de trabajo y fluctuante atención responden mejor ante pocas opciones de respuesta (Rodríguez et. al., 2011). Estos déficits también son un hándicap a la hora de pasar pruebas costosas o largas, por ello el hecho del que el DAS sea un instrumento breve ha sido considerada una gran ventaja (Rodríguez et. al., 2011).

Por lo que se refiere a las características psicométricas de la escala, los ítems han mostrado una excelente consistencia interna, mostrando una elevada fiabilidad.

En otro orden de cosas, este proceso de construcción-validación nos ha permitido reflexionar alrededor de la importancia de valorar todos los factores que influyen en una evaluación y de las dificultades que implican el uso de autoinformes. Todo ello, nos ha llevado a valorar la importancia del papel del evaluador durante la administración de la escala, convirtiéndose en un elemento imprescindible. Así, sería aconsejable que el profesional actuara de mediador entre el instrumento y el evaluado, proporcionando una explicación adaptada del mismo que asegure su comprensión. Esto contribuiría a una mejor comprensión de los conceptos al proporcionar una explicación más rica y personalizada.

Por ello, se hace evidente, que el profesional que realice las evaluaciones debe poseer siempre amplios conocimientos no solo sobre el instrumento en sí (qué evalúa cada ítem, como es su formato de respuesta, etc.), sino también sobre los usuarios a los que se le va a pasar (nivel de comprensión, nivel en lecto-escritura, etc.).

\section{REFERENCIAS BIBLIOGRÁFICAS}

Consejería para la Igualdad y Bienestar Social de la Junta de Andalucía (2008) "Mujeres con discapacidad y violencia sexual: guía para profesionales", disponible en www.juntadeandalucia.es/.../ Personas Discapacidad_guia violencia sexual.pdf

Couwenhoven, T. (2013). La educación sexual es la prevención del abuso sexual. Revista Síndrome de Down, vol. 30, pp. 9.

Foro de Vida Independiente (2005): "Resumen de la Propuesta del Foro de Vida Independiente a la futura" "Ley Estatal de Protección Social a las Personas Dependientes". Diario de Sesiones del Congreso de los Diputados, Año 2005, Núm. 222, Sesión núm. 7. Disponible en http://www.minusval2000.com/relaciones/ vidalndependiente/resumen_Propuesta_Foro_futura_Ley_independencia.html 
González Correa, O.S. y Ramos Pérez, C.C. (2016) Abuso sexual en personas con discapacidad intelectual (tests de pregrado). Universidad de La Laguna, Tenerife.

Liou, W. Y. (2014). An Illustrated Scale Measuring the Sexual Abuse Prevention Knowledge of Female High School Students with Intellectual Disabilities in Taiwan. Sexuality and Disability, 32(2), 135-151.

Lyden, M. (2007) Assessment of sexual consent capacity. Sexuality and Disability, 25, 3-20

Recio, M., Galindo, L., Cendra, J., Alemany, A., Martorell, A, y Villaró, A. (2014) Abuso y discapacidad intelectual: Orientaciones para la prevención y la actuación. FEAPS Madrid y Fundación Carmen Pardo-Valcarce

Rodríguez, M., López, M., García, A., \& Rubio, J. C. (2011). Funciones ejecutivas y discapacidad intelectual: evaluación y relevancia. Campo Abierto, 30, 2, 79-93.

Verdugo, M. Á., Alcedo, M. Á., Bermejo, B. y Aguado, A. L. (2002). E abuso sexual en personas con discapacidad intelectual. Psicothema, vol. 14, pp. 124. 